\title{
Dopamine Use and Its Consequences in The Intensive Care Unit: a Cohort Study Utilizing the Japanese Intensive care Patient Database
}

Reina Suzuki ( $\square$ reinasuzuki.21@gmail.com )

Jichi Medical University Saitama Medical Center

Shigehiko Uchino

Jichi Medical University Saitama Medical Center

Yusuke Sasabuchi

Jichi Medical University

Alan Kawarai Lefor

Jichi Medical University

Masamitsu Sanui

Jichi Medical University Saitama Medical Center

\section{Research Article}

Keywords: Intensive care unit, Dopamine, Low-dose Dopamine, Catecholamine, Cardiovascular, Critical care

Posted Date: December 30th, 2021

DOI: https://doi.org/10.21203/rs.3.rs-1205031/v1

License: (c) (1) This work is licensed under a Creative Commons Attribution 4.0 International License. Read Full License

Version of Record: A version of this preprint was published at Critical Care on April 2nd, 2022. See the published version at https://doi.org/10.1186/s13054-022-03960-y. 


\section{Abstract}

Background: Dopamine is used to treat patients with shock in intensive care units (ICU) throughout the world, despite recent evidence against its use. Current practice patterns for the use of dopamine have not been reported.

Methods: The Japanese Intensive Care PAtient Database (JIPAD), the largest intensive care database in Japan, was utilized. Inclusion criteria included: 1) age 18 years or older, 2) admitted to the ICU for reasons other than procedures, 3) ICU length of stay of 24 hours or more, and 4) treatment with either dopamine or noradrenaline within 24 hours of admission. The primary outcome was in-hospital mortality. Multivariable regression analysis was performed, followed by a pre-planned propensity score-matched analysis.

Results: Of the 132,354 case records, 14594 records from 56 facilities were included in this analysis. Dopamine was administered to 4653 patients and noradrenaline to 11844 . There was no statistically significant difference in facility characteristics between frequent dopamine users $(\mathrm{N}=28)$ and infrequent users $(\mathrm{N}=28)$. Patients receiving dopamine had more cardiovascular diagnosis codes $(70 \%$ vs. $42 \%$; p $<0.01)$, more post-elective surgery status ( $60 \%$ vs. $31 \%)$, and lower APACHE III scores compared to patients given noradrenaline alone (70.7 vs. 83.0; $p<0.01$ ). Multivariable analysis showed an odds ratio for in-hospital mortality of 0.86 [95\% Cl: $0.71-1.04$ ] in the dopamine $<=5 \mu \mathrm{g} / \mathrm{kg} / \mathrm{min}$ group, 1.50 [95\% Cl: $1.18-1.82$ ] in the $5-15 \mu \mathrm{g} / \mathrm{kg} / \mathrm{min}$ group, and 3.30 [95\% Cl: $1.19-9.20$ ] in the $>15 \mu \mathrm{g} / \mathrm{kg} / \mathrm{min}$ group. In 1:1 propensity score matching for dopamine use (3322 pairs), there was no statistically significant difference for in-hospital mortality between the dopamine group and no dopamine group (13.0\% vs. $12.0 \%, p=0.21)$, but ICU length of stay was significantly longer in the dopamine group (mean 7.4 days vs. 6.6 days, $\mathrm{p}<0.01)$.

Conclusion: Dopamine is still widely used in Japan. The results of this study suggest detrimental effects of dopamine use specifically at a high dose, although there is no significant association with increased in-hospital mortality.

Trial registration: Retrospectively registered upon approval of the Institutional Review Board and the administration office of JIPAD.

\section{Background}

Since Goldberg et al. reported that administration of dopamine to patients with end-stage congestive heart failure resulted in increased cardiac output and sodium diuresis (1), dopamine has been used to treat patients with shock. It was thought that treatment with dopamine would benefit patients at risk of developing acute renal failure due to its vasodilatory effects when used at a low dose. Subsequent studies, however, refuted the beneficial effects of dopamine on patient-centered outcomes in the contexts of renal protection (2-6) and as a vasopressor (7-10). It is now generally accepted that dopamine causes more harm than benefits and is not recommended for patients with shock $(4,11-13)$ based on the 
findings that dopamine is associated with an increased risk of tachyarrhythmias and possibly increased mortality compared to noradrenaline. (2)

The latest Surviving Sepsis Campaign Guidelines 2016 recommend noradrenaline as the drug of choice and recommend dopamine "only in highly selected patients (e.g., patients with a low risk of tachyarrhythmias and absolute or relative bradycardia)".(14) The guideline clearly states that they "recommend against using low-dose dopamine for renal protection". In a recently published article describing online survey results from 839 members of The European Society of Intensive Care Medicine in 82 countries, Scheeren et al. reported that only $2 \%$ of survey responders chose dopamine as the first choice for the treatment of patients with shock. (15) Despite this evidence, dopamine is still used in some countries including Japan. (16-21) In a study conducted by Iwagami et al. to evaluate the role of polymyxin B hemoperfusion in Japanese patients with abdominal septic shock between 2007-2011, dopamine was given to more than $80 \%$ of patients. In a large database-based cohort study from the United States, dopamine was reported to be the most commonly used vasopressor in combination with noradrenaline from 2008-2013.(22) Indeed, there are multiple studies from different countries which report the continued use of dopamine in recent years. $(19,21,23)$

Given the risks associated with dopamine administration, there is an urgent need to evaluate the current situation of dopamine use so that appropriate measures can be taken. We conducted this retrospective analysis of the largest database of critically ill patients in Japan to identify current patterns of dopamine use.

\section{Methods}

\section{Database}

This study was approved by the Institutional Board Review at our institution as well as the administration office of the Japanese Intensive Care Case Database (JIPAD)(24). JIPAD is the largest domestic database of critically ill patients managed by the Japanese Society of Intensive Care Medicine, which was established in 2014 and involved 89 participating facilities and 78 hospitals as of November 2020. The data were anonymized upon transfer to the database. Investigators are granted access to the data set upon approval of their request by the JIPAD administrative office. For this study, all existing case records with all data elements in the Case Report Form were requested and approved.

\section{Patients}

Inclusion criteria included: 1) age 18 years or older, 2) admitted to the ICU for reasons other than procedures e.g. central line insertion, 3) ICU length of stay of equal to or more than 24 hours, and 4) use of either dopamine or noradrenaline during the first 24 hours of ICU stay. Patients fulfilling all the above criteria were included for analysis. The exclusion criterion was the presence of missing data required for multivariable analysis. 


\section{Outcomes}

Participating facilities were classified into two groups: dopamine-frequently using facilities and dopamine-infrequently using facilities based on the percentage of patients treated with dopamine with a cut-off at the median value. Stacked bar plots for facilities were made for: 1) all patients, 2) patients with infectious disease diagnosis codes only, 3) patients with cardiovascular disease codes only, and 4) patients with diagnosis codes other than infectious diseases or cardiovascular diseases, to visualize the proportion of patients treated with dopamine only, dopamine + noradrenaline, and noradrenaline only. The primary outcome was in-hospital mortality. The secondary outcomes were death at the time of ICU discharge, ICU length of stay, hospital length of stay, and duration of the first episode of mechanical ventilation.

\section{Variables}

Data in the original dataset included: facility identification number, year, age, gender, date of hospital admission/discharge, weight, height, comorbidities (human immunodeficiency virus / acquired immune deficiency syndrome, congestive heart failure, respiratory failure, liver failure, cirrhosis, use of immunosuppressants, undergoing hemodialysis, lymphoma, acute leukemia, cancer with metastases), days before ICU admission after hospital admission, cardiac arrest leading to that ICU admission, activation of Rapid Response Team / Medical Emergency Team leading to that ICU admission, date/time of ICU admission/discharge, the reason for ICU admission (1. transfer from the ward, 2) admission through the emergency room, 3) ICU admission following elective surgery, 4) admission following urgent surgery, and 5) other), diagnosis text, diagnosis code, Glasgow Coma Scale, the maximum serum lactate level during the first 24 hours of ICU admission, maximum/minimum laboratory values during the first 24 hours after ICU admission, the maximum value of serum bilirubin, and lactate, minimum value of platelet count, urine output during the first 24 hours after ICU admission, acute kidney injury/mechanical ventilation during the first 24 hours after ICU admission, APACHE III/SAPS II score, SOFA score, use of dopamine / dobutamine / adrenaline / noradrenaline during the first 24 hours of ICU admission, date/time of initiation and discontinuation of mechanical ventilation, ICU discharge outcome, hospital discharge outcome (alive, transferred, dead), and readmission to the ICU. Other data elements are presented in Supplemental Table 1. The variables collected during the first 24 hours were treated as the baseline values. Catecholamine variables were classified as: 1 ) dopamine (no use, $<=5 \mu \mathrm{g} / \mathrm{kg} / \mathrm{min},>5$ and $<=15 \mu \mathrm{g} / \mathrm{kg} / \mathrm{min},>15 \mu \mathrm{g} / \mathrm{kg} / \mathrm{min}$ ), 2) noradrenaline (no use, $<=0.1 \mu \mathrm{g} / \mathrm{kg} / \mathrm{min},>0.1 \mu \mathrm{g} / \mathrm{kg} / \mathrm{min}$ ), 3) dobutamine (yes/no), and 4) adrenaline (no use, $<=0.1 \mu \mathrm{g} / \mathrm{kg} / \mathrm{min},>0.1 \mu \mathrm{g} / \mathrm{kg} / \mathrm{min}$ ). A new, binary cardiovascular code was assigned when the patient had a cardiac disease code as the primary diagnosis code. A new, binary infection code was assigned when the primary disease code was one of the infectionassociated codes as per the JIPAD dictionary (Last updated December 25, 2020).

\section{Statistical Analysis}

Multivariable logistic regression analysis with a generalized estimating equation was conducted to assess the effect of dopamine use on the primary outcome, accounting for differences in practice among 
the facilities. In the generalized estimating equation models, the dopamine variable was treated as a categorical value with four levels including:1) no use, 2) equal to or less than $5 \mu \mathrm{g} / \mathrm{kg} / \mathrm{min}, 3$ ) more than 5 but equal to or less than $15 \mu \mathrm{g} / \mathrm{kg} / \mathrm{min}$, and 4) equal to or greater than $15 \mu \mathrm{g} / \mathrm{kg} / \mathrm{min}$. Predictor variables in the model were selected by the study team based on their clinical importance, especially when the variables were previously reported to predict outcomes in critically ill patients including postoperative state, (25) admission from the ward, (26) urgent/emergent admission, (27) time from hospital admission to ICU admission, $(28,29)$ and use of mechanical ventilation.(30) The primary predictor variable was a categorical variable representing 1 ) dopamine only, 2) dopamine and noradrenaline, and 3) noradrenaline only.

To examine the specific effect of dopamine on primary and secondary outcomes, a pre-planned propensity score-matched analysis was conducted. The propensity scores for dopamine administration were calculated for study patients using a logistic regression model with the generalized estimating equation. The variables used to calculate propensity scores for treatment with dopamine are presented in Supplemental Table 1. The R package "Matching" was employed to perform a one-to-one matching of treatment vs control based on the calculated propensity scores. To check the balance between the two groups, the baseline characteristics were presented with standardized mean differences.

To explore the effects of dopamine on the outcomes of patients with cardiovascular disease or infection, pre-planned subgroup analyses were conducted using data from patients with a newly assigned, dichotomized primary disease code of 1) cardiovascular, 2) infection, or 3) other (neither 1 nor 2). Continuous variables were presented with a mean ( \pm standard deviation) and median (interquartile range) as appropriate. Categorical variables were reported with a number (\%). Statistical significance was tested with a t-test for continuous variables and the chi-square test for categorical variables. The results of multivariable analysis were presented with an odds ratio with $95 \%$ confidence intervals. A p-value of 0.05 (bilateral) was considered statistically significant. All statistical analyses were conducted with $\mathrm{R}$ version 4.0.2. (R Foundation for Statistical Computing, Vienna, Austria)

\section{Results}

In total, 132,354 patient records dated from 2015 to 2020 were available, with 14,594 included in this analysis (Figure 1). Dopamine was administered to $32 \%$ of all patients, with $13 \%$ with receiving dopamine in combination with noradrenaline. Among patients for whom dopamine was used, $82 \%$ received a low dose ( $<=5 \mu \mathrm{g} / \mathrm{kg} / \mathrm{min}$ ), $16.9 \%$ received a medium dose (dopamine $>5$ and $<=15 \mu \mathrm{g} / \mathrm{kg} / \mathrm{min}$ ), and the remainder $1.1 \%$ received a high dose ( $>15 \mu \mathrm{g} / \mathrm{kg} / \mathrm{min}$ ). Noradrenaline was administered to $81 \%$ of all patients. The mean age of the patients was 69.4 years and $65.4 \%$ were male. The median ICU stay was 4.0 days (IQR: 2.5-7.5) and the median hospital stay was 29 days (IQR: 18-53). The baseline epidemiological characteristics of the patients in the three, mutually exclusive groups (dopamine only, dopamine + noradrenaline, and noradrenaline only) were summarized in Table 1. Congestive heart failure was more common in the dopamine group compared to the noradrenaline only group (4.0\% vs $2.5 \%$, $\mathrm{p}<0.01)$. Cardiovascular diagnosis codes were more prevalent in the dopamine group than the 
noradrenaline only group. Infection diagnosis codes were more prevalent in the noradrenaline only group than the dopamine group ( $69.6 \%$ vs $41.5 \%, p<0.01 ; 27.3 \%$ vs $6.4 \%, p<0.01$, respectively). The highest APACHE III and SAPS II during the first 24 hours were higher in the noradrenaline only group than the dopamine group ( 83.0 vs $70.7, p<0.01 ; 47.3$ vs $39.6, p<0.01$, respectively). Baseline vital signs and laboratory data were presented separately in Supplemental Table 1.

The characteristics of the participating 56 facilities were presented in Supplemental Table 2. Fifty-six facilities included in the analysis were divided into two groups: dopamine infrequent users $(\mathrm{N}=28)$ and dopamine frequent users $(\mathrm{N}=28)$ with a cutoff value for this differentiation set at the median value of the percentage of patients treated with dopamine (19.8\%; IQR $4.9-48.2 \%$, minimum $0.0 \%$, maximum 96.2\%). Public hospitals were more common among dopamine infrequent users compared to dopamine frequent users ( $57.1 \%$ vs $25.0 \%$ ) while university hospitals were more common among dopamine frequent users (32.1\% vs $53.6 \%$ ). There were no statistically significant differences in the number of hospital beds or ICU beds, number of board-certified intensivists, or nurses. Figure 2 visually represented a wide variation of percentages of patients who received dopamine (light grey), dopamine and noradrenaline (grey), and noradrenaline (dark grey) among the participating facilities (each bar on the $x$ axis represent each facility) noted above. When the patients were broken down into 3 disease categories per the primary disease code i.e. cardiovascular, infection, and other (non-cardiovascular, non-infectious), dopamine was found to be more widely used in cardiovascular disease, compared to infection or other diseases. The median proportions of patients treated on dopamine (including those both on dopamine and noradrenaline) at each facility were 0.20 [IQR: 0.05-0.49] for all patients, 0.41 [IQR: 0.09-0.71] for cardiovascular, 0.10 [IQR: $0.04-0.26$ ] for infection, and 0.22 [IQR: $0.08-0.48$ ] for other diagnosis code.

A univariable logistic regression with a generalized estimating equation with death at hospital discharge as the outcome variable and dopamine as the predictor variable yielded an odds ratio (OR) 0.39 (95\% Cl: 0.31-0.51) for dopamine $<=5 \mu \mathrm{g} / \mathrm{kg} / \mathrm{min}$, OR $1.39(95 \% \mathrm{Cl}: 1.11-1.73)$ for dopamine $>5$ and $<=15$ $\mu \mathrm{g} / \mathrm{kg} / \mathrm{min}$, and OR 4.87 (95\% Cl: 2.85-8.34) for dopamine $>15 \mu \mathrm{g} / \mathrm{kg} / \mathrm{min}$ (no use as reference). When adjusted for age, gender (female as reference), comorbidities, days before ICU after hospital admission, cardiopulmonary resuscitation, the reason for ICU admission (others as reference), diagnosis code, APACHE III, the maximum lactate level at baseline, mechanical ventilation at baseline, AKI at baseline, dobutamine use, and adrenaline use, the higher doses of dopamine were still associated with a higher inhospital mortality rate (Table 2 ).

\section{Propensity-matched analysis}

Subsequently, a pre-planned propensity-matched analysis was conducted on the data after the inclusion process. In total, 3322 pairs were made upon propensity score matching. The baseline characteristics of the pairs were presented in Table 3 and Supplemental Table 3, showing well-balanced groups with standardized mean differences $<0.1$. Although no data for sepsis was available in the JIPAD, when stratified by infection-related diagnosis code and SOFA score of two or more, there were 455 potential septic patients (238 in no dopamine group and 217 in dopamine group) among 6644 patients included in 
the propensity-matched analysis. The primary and secondary outcomes in these two groups were presented in Table 4. There was no statistically significant difference either in death at the time of ICU discharge or death at the time of hospital discharge between the two groups. ICU length of stay was significantly longer in the dopamine group with a difference of almost one day. There was no statistically significant difference in the duration of the first episode of mechanical ventilation.

\section{Sub-group analysis}

Since cardiovascular disease and infection are the two main categories patients to whom catecholamines are administered, sub-group analyses were conducted on these specific subgroups (Supplemental Tables 4-1, 4-2, 4-3). This analysis showed significantly worse primary outcomes for patients with a cardiovascular diagnosis treated with dopamine, while these associations were not found for patients with a diagnosis of infection or with neither a cardiovascular nor an infection diagnosis.

The propensity-matched analyses were attempted respectively on the three different dopamine dose ranges vs no dopamine, leaving no dopamine vs dopamine $<=5 \mathrm{mg} / \mathrm{kg} / \mathrm{min}$ as the only successful analysis due to instability of the models with the other dopamine dose ranges (Supplemental Table 5). The propensity-matched analyses were conducted on different subgroups of patients as well i.e. surgical patients only (Supplemental Table 6-1, 6-2 for cardiac surgical patients only, 6-3 for non-cardiac surgical patients only), and patients admitted through emergent admissions only (Supplemental Table 7). The results of these subgroup analyses were similar to the results of the original propensity-matched analysis presented in Table 4.

The propensity-matched analysis on all patients with the results of the dopamine group stratified by the three different dose ranges was presented in Supplemental Table 8. Supplemental Table 8 showed higher hospital and ICU mortality as the dopamine dose increases.

\section{Discussion}

These results show that dopamine is widely used in ICUs in Japan, most commonly for patients who underwent elective cardiac surgery. There were no significant differences in hospital characteristics between dopamine frequent-using facilities compared with infrequent-using facilities. Importantly, a dopamine dose $>5 \mu \mathrm{g} / \mathrm{kg} / \mathrm{min}$ was associated with a higher probability of in-hospital mortality in a dosedependent manner in multivariable analysis. The propensity score-matched analysis, where the disease severity was well balanced between the dopamine group vs no dopamine group, did not show a difference in the risk of death at ICU discharge or hospital discharge whether or not dopamine had been administered. However, this analysis showed a longer ICU stay by almost one day in the dopamine group. A pre-planned subgroup analysis showed a significantly higher in-hospital mortality in patients with cardiovascular disease treated with dopamine, although such an association was not found in patients with infections or other diagnoses. Dopamine administration was associated with an increased ICU length of stay both in patients with cardiovascular disease and infection. 
As stated in the Surviving Sepsis Campaign Guidelines 2016, the literature on the treatment of shock after 2010 - when the landmark Sepsis Occurrence in Acutely III Patients (SOAP) II trial was published - do not support dopamine use in treating patients with shock in general. $(11,12,31)$ Despite this fact, dopamine use is still found in the literature in recent years. As noted above, Vail et al. from the United States reported that dopamine was the most commonly used (6.2\%) vasopressor in combination with noradrenaline among 584,421 patients with septic shock studied from 2008-2013.(22) In a nationwide survey among intensive care physicians in China conducted by Pei et al. in 2012 , as many as $68 \%$ of the responders chose dopamine as the agent of choice for the treatment of patients with cardiogenic shock. (23) Chittawatanarat et al. found that dopamine was the most commonly used (63\%) vasopressor to treat patients with traumatic shock and the second most common (28\%) drug for the treatment of patients with septic shock in the Thai-shock survey 2013.(21) Considering practice patterns in Japan, there is very limited literature on dopamine use and preliminary data were available only as incidental findings. In a retrospective study that assessed the role of postoperative polymyxin B administration in patients undergoing open abdominal surgery during 2007-2011 by Iwagami et al., dopamine was used in more than $80 \%$ of patients - much higher than noradrenaline (53\%) or dobutamine (10\%). (32) Tagami et al. reported in 2014 that dopamine was the most prevalently (80\%) used catecholamine for patients already treated with noradrenaline in their cohort. The results of the present study show that dopamine is commonly used in JIPAD participating facilities as of 2018-2019. As many as 14 out of 56 facilities used dopamine for more than $50 \%$ of patients and 2 of them used dopamine for $>90 \%$ of patients, suggesting a low threshold for dopamine use in some facilities. While the situation in Japan might not be applicable in other countries, these results suggest that the deleterious effects of dopamine may be underrecognized in certain situations.

In the present study, dopamine was predominantly (82\%) used at a low dose (less than $5 \mu \mathrm{g} / \mathrm{kg} / \mathrm{min}$ ), which suggests the prevailing notion of the renal-protective effects of dopamine among physicians as of 2018-2019. While low-dose dopamine was initially expected to induce natriuresis in patients with endstage congestive heart failure through vasodilation, the benefits of low-dose dopamine on patient outcomes were subsequently refuted in many studies. The landmark randomized controlled trial conducted by the Australian and New Zealand Intensive Care Society (ANZICS)(2) revealed no reduction in the incidence of acute renal failure, the requirement for hemodialysis, or 28-day mortality with dopamine use in patients with sepsis and oliguria. Accordingly, three large systematic reviews which included this trial failed to show clinical benefits of low-dose dopamine, leading to an elimination of dopamine from clinical practice as a renal-protective agent. (4-6) The reason for the widespread use of low dose dopamine in the present study is difficult to determine, but it suggests the challenging nature of knowledge transmission or knowledge updates in clinical practice. The odds ratio for the hospital mortality for the low dose dopamine in the current study was lower than those for higher dose groups in the multivariable analysis (Table 2) as well as in the propensity-score matching (Supplemental Table 8), likely reflecting the less disease severity in the patients treated with low-dose dopamine. The results were not statistically significant, however, and consistent with the study from ANZICS in 2000, which showed no mortality benefits with the low dose dopamine as described above. 
While most previous studies of dopamine use included patients with septic shock, Hiemstra et al. recently conducted a systematic review and meta-analysis with 17 trials, including only patients with cardiac dysfunction, with a left ventricular ejection fraction $<45 \%$. As opposed to previous studies of patients with septic shock, the study did not show a significant association between dopamine use and mortality. In the patient population included in the present study which included mostly post-cardiac surgery patients possibly with some cardiac dysfunction, a higher mortality along with a higher dopamine dose was suggested in contrast to results in the study by Hiemstra et al. This difference could partially be explained by a difference in the dosage of dopamine used in the studies. In the cohort in the present study, only a dopamine dose more than $5 \mu \mathrm{g} / \mathrm{kg} / \mathrm{min}$ was associated with higher mortality in a dose-dependent manner, while the dose range studied in Hiemstra's work was less than in the present study (low dose: 4 $\mu \mathrm{g} / \mathrm{kg} / \mathrm{min}$, moderate dose: $4-10 \mu \mathrm{g} / \mathrm{kg} / \mathrm{min}$ ).

Catecholamine type and doses recommended for vasoplegia in patients after cardiopulmonary bypass are not well established, though vasoplegic shock or vasoplegic syndrome is not uncommon in patients after cardiac surgery (9-44\%). (33-35) In a systematic review that assessed catecholamine use after cardiac surgery by Egi in 2007, (36) dopamine use was neither recommended nor discouraged due to a lack of evidence. A recently published consensus statement for the use of vasopressor therapy in patients undergoing cardiac surgery from Europe strongly recommends against dopamine administration for treating vasoplegic shock after cardiac surgery with an agreement of $100 \%$. Although there were no randomized controlled trials which included this specific patient population in our extensive literature search, previous studies did not support dopamine use as the treatment of choice in patients after cardiopulmonary bypass. $(37,38)$ Considering the results in the existing literature and the results of the present study showing deleterious effects of dopamine, taken together, dopamine should not be used to treat patients after cardiac surgery or in patients with sepsis. Combined efforts at the individual level and at the facility / society level are needed to optimize dopamine use in clinical practice.

This is the largest study that assessed dopamine use and its consequences in ICUs from a single Asian country, utilizing the largest domestic critical care registry (JIPAD) in Japan. However, there are certain limitations to the present study, other than the usual limitations implicit in a retrospective study. First, patients with missing data needed for multivariable models were excluded, which might introduce selection bias. Specifically, albumin, platelet, and bilirubin variables had many missing values, leading to exclusion of these variables from the multivariable models. Second, there was no data regarding tachycardia or cardiac arrhythmias, unlike previous studies which used arrhythmias as an outcome. The available heart rate data were maximum and minimum heart rate only during the first 24 hours, which were presented as baseline data. Third, the context in which dopamine was used might not be appropriately reflected in the diagnosis code. Specifically, post-operative cardiogenic shock and postoperative vasodilatory shock were difficult to differentiate from the diagnosis codes only. Due to this problem, the specific indication for dopamine use was unclear, expecting either a renal-protective effect, vasopressor effect, or both. Fourth, the exact doses and duration of each catecholamine were not available - which might be one of the common but significant limitations of any databases requiring manual data entry. Any catecholamine requirement outside of the first 24 hour-window was thus not 
perceived in the current study. It should also be noted that the patient population in the present study seemed to be less acutely ill when compared to previous cohorts such those as in the SOAP (39) or SOAP II (7) studies, where ICU mortality was about $30 \%$ in the former and the 28-day mortality was approximately $50 \%$ in the latter - while the in-hospital mortality in the population in the present study was $18 \%$.

\section{Conclusion}

To the best of our knowledge, this is the largest study to describe dopamine use in patients in the intensive care unit after the SOAP II trial, utilizing a domestic database administered by the Japanese Society of Intensive Care Medicine. Dopamine was found to be used widely as of 2018-2019, most notably in patients after cardiac surgery, and at a low dose. Dopamine use of $>5 \mu \mathrm{g} / \mathrm{kg} / \mathrm{min}$ was associated with poor clinical outcomes in patients in this study, similar to the results of previous studies, supporting the need to change clinical practice for the use of dopamine.

\section{Abbreviations}

AKl: Acute kidney injury

APACHE: Acute physiology and chronic health evaluation

ICU: Intensive Care Unit

IQR: Interquartile range

OR: Odds ratio

SAPS: Simplified acute physiology score

SD: Standard deviation

\section{Declarations}

Ethics approval and consent to participate: Approval obtained from the administration office of the Japanese Intensive care PAtient Database and the Institutional Review Board of Jichi Medical University Saitama Medical Center (Request number: $\square$ S20-207).

Consent for publication: Included in the ethics approval process above.

Availability of data and materials: The datasets generated and/or analyzed during the current study are not available since the dataset were obtained from the Japanese Intensive care. PAtient Database through a formal request / approval process as above but are available from the corresponding author on reasonable request. 
Competing interests: The authors declare that they have no competing interests.

Funding: Not applicable.

Authors' contributions: RS is responsible for the analysis and the first draft of the manuscript. YS contributed as an advisor of statistical analysis. MS, AKL, and SU contributed to the subsequent drafts, with AKL's context and grammar check before finalization.

Conflict of interest: No authors have conflicts of interest to declare.

Acknowledgements: Not applicable.

Authors' information:

1. Department of Anesthesiology and Intensive Care, Saitama Medical Center, Jichi Medical University

2. Data Science Center, Jichi Medical University

3. Department of Surgery, Jichi Medical University

\section{References}

1. Goldberg LI, McDonald RH, Jr., Zimmerman AM. Sodium Diuresis Produced by Dopamine in Patients with Congestive Heart Failure. N Engl J Med. 1963;269:1060-4.

2. Low-dose dopamine in patients with early renal dysfunction: a placebo-controlled randomised trial. The Lancet. 2000;356(9248):2139-43.

3. Marik PE. Low-dose dopamine: a systematic review. Intensive Care Med. 2002;28(7):877-83.

4. Holmes CL, Walley KR. Bad medicine: low-dose dopamine in the ICU. Chest. 2003;123(4):1266-75.

5. Debaveye YA, Van den Berghe $\mathrm{GH}$. Is there still a place for dopamine in the modern intensive care unit? Anesth Analg. 2004;98(2):461-8.

6. Venkataraman R. Can we prevent acute kidney injury? Crit Care Med. 2008;36(4 Suppl):S166-71.

7. De Backer D, Biston P, Devriendt J, Madl C, Chochrad D, Aldecoa C, et al. Comparison of dopamine and norepinephrine in the treatment of shock. N Engl J Med. 2010;362(9):779-89.

8. Sakr Y, Reinhart K, Vincent JL, Sprung CL, Moreno R, Ranieri VM, et al. Does dopamine administration in shock influence outcome? Results of the Sepsis Occurrence in Acutely III Patients (SOAP) Study. Crit Care Med. 2006;34(3):589-97.

9. De Backer D, Aldecoa C, Njimi H, Vincent JL. Dopamine versus norepinephrine in the treatment of septic shock: a meta-analysis*. Crit Care Med. 2012;40(3):725-30. 
10. Avni T, Lador A, Lev S, Leibovici L, Paul M, Grossman A. Vasopressors for the Treatment of Septic Shock: Systematic Review and Meta-Analysis. PLoS One. 2015;10(8):e0129305.

11. Marinosci GZ, De Robertis E, De Benedictis G, Piazza O. Dopamine Use in Intensive Care: Are We Ready to Turn it Down? Transl Med UniSa. 2012;4:90-4.

12. Annane D. Physicians no longer should consider dopamine for septic shock!*. Crit Care Med. 2012;40(3):981.

13. De Backer D, Foulon P. Minimizing catecholamines and optimizing perfusion. Crit Care. 2019;23(Suppl 1):149.

14. Petros S, John S. [The 2016 Surviving Sepsis Campaign sepsis guideline]. Medizinische Klinik, Intensivmedizin und Notfallmedizin. 2017;112(5):454-8.

15. Scheeren TWL, Bakker J, De Backer D, Annane D, Asfar P, Boerma EC, et al. Current use of vasopressors in septic shock. Ann Intensive Care. 2019;9(1):20.

16. Yang JH, Choi KH, Ko YG, Ahn CM, Yu CW, Chun WJ, et al. Clinical Characteristics and Predictors of InHospital Mortality in Patients With Cardiogenic Shock: Results From the RESCUE Registry. Circ Heart Fail. 2021;14(6):e008141.

17. Myc LA, Stine JG, Chakrapani R, Kadl A, Argo CK. Vasopressin use in critically ill cirrhosis patients with catecholamine-resistant septic shock: The CVICU cohort. World J Hepatol. 2017;9(2):106-13.

18. Kollind M, Wickbom F, Wilkman E, Snackestrand MS, Holmen A, Oldner A, et al. Shock treatment in a cohort of Scandinavian intensive care units in 2014. Acta Anaesthesiol Scand. 2016;60(7):945-57.

19. Nguyen HB, Lu S, Possagnoli I, Stokes P. Comparative Effectiveness of Second Vasoactive Agents in Septic Shock Refractory to Norepinephrine. J Intensive Care Med. 2017;32(7):451-9.

20. Kubler A, Adamik B, Durek G, Mayzner-Zawadzka E, Gaszynski W, Karpel E, et al. Results of the severe sepsis registry in intensive care units in Poland from 2003-2009. Anaesthesiol Intensive Ther. 2015;47(1):7-13.

21. Chittawatanarat K, Patjanasoontorn B, Rungruanghiranya S. Thai-shock survey 2013: survey of shock management in Thailand. J Med Assoc Thai. 2014;97 Suppl 1:S108-18.

22. Vail EA, Gershengorn HB, Hua M, Walkey AJ, Wunsch H. Epidemiology of Vasopressin Use for Adults with Septic Shock. Ann Am Thorac Soc. 2016;13(10):1760-7.

23. Pei XB, Ma PL, Li JG, Du ZH, Zhou Q, Lu ZH, et al. Extensive variability in vasoactive agent therapy: a nationwide survey in Chinese intensive care units. Chin Med J (Engl). 2015;128(8):1014-20. 
24. Irie $\mathrm{H}$, Okamoto $\mathrm{H}$, Uchino $\mathrm{S}$, Endo H, Uchida M, Kawasaki T, et al. The Japanese Intensive care PAtient Database (JIPAD): A national intensive care unit registry in Japan. J Crit Care. 2020;55:86-94.

25. Onwochei DN, Fabes J, Walker D, Kumar G, Moonesinghe SR. Critical care after major surgery: a systematic review of risk factors for unplanned admission. Anaesthesia. 2020;75 Suppl 1:e62-e74.

26. Harris S, Singer M, Sanderson C, Grieve R, Harrison D, Rowan K. Impact on mortality of prompt admission to critical care for deteriorating ward patients: an instrumental variable analysis using critical care bed strain. Intensive Care Med. 2018;44(5):606-15.

27. Galloway M, Hegarty A, McGill S, Arulkumaran N, Brett SJ, Harrison D. The Effect of ICU Out-of-Hours Admission on Mortality: A Systematic Review and Meta-Analysis. Crit Care Med. 2018;46(2):290-9.

28. Goldhill DR, McNarry AF, Hadjianastassiou VG, Tekkis PP. The longer patients are in hospital before Intensive Care admission the higher their mortality. Intensive Care Med. 2004;30(10):1908-13.

29. Groenland CNL, Termorshuizen F, Rietdijk WJR, van den Brule J, Dongelmans DA, de Jonge E, et al. Emergency Department to ICU Time Is Associated With Hospital Mortality: A Registry Analysis of 14,788 Patients From Six University Hospitals in The Netherlands. Crit Care Med. 2019;47(11):1564-71.

30. Bickenbach J, Fries M, Rex S, Stitz C, Heussen N, Rossaint R, et al. Outcome and mortality risk factors in long-term treated ICU patients: a retrospective analysis. Minerva Anestesiol. 2011;77(4):427-38.

31. Rhodes A, Evans LE, Alhazzani W, Levy MM, Antonelli M, Ferrer R, et al. Surviving Sepsis Campaign: International Guidelines for Management of Sepsis and Septic Shock: 2016. Intensive Care Med. 2017;43(3):304-77.

32. Iwagami M, Yasunaga H, Doi K, Horiguchi H, Fushimi K, Matsubara T, et al. Postoperative polymyxin B hemoperfusion and mortality in patients with abdominal septic shock: a propensity-matched analysis. Crit Care Med. 2014;42(5):1187-93.

33. Carcoana OV, Mathew JP, Davis E, Byrne DW, Hayslett JP, Hines RL, et al. Mannitol and dopamine in patients undergoing cardiopulmonary bypass: a randomized clinical trial. Anesth Analg. 2003;97(5):12229.

34. Tuman KJ, McCarthy RJ, O'Connor CJ, Holm WE, Ivankovich AD. Angiotensin-converting enzyme inhibitors increase vasoconstrictor requirements after cardiopulmonary bypass. Anesth Analg. 1995;80(3):473-9.

35. Mets B, Michler RE, Delphin ED, Oz MC, Landry DW. Refractory vasodilation after cardiopulmonary bypass for heart transplantation in recipients on combined amiodarone and angiotensin-converting enzyme inhibitor therapy: a role for vasopressin administration. J Cardiothorac Vasc Anesth. 1998;12(3):326-9. 
36. Egi M, Bellomo R, Langenberg C, Haase M, Haase A, Doolan L, et al. Selecting a vasopressor drug for vasoplegic shock after adult cardiac surgery: a systematic literature review. Ann Thorac Surg. 2007;83(2):715-23.

37. Fellahi JL, Parienti JJ, Hanouz JL, Plaud B, Riou B, Ouattara A. Perioperative use of dobutamine in cardiac surgery and adverse cardiac outcome: propensity-adjusted analyses. Anesthesiology. 2008;108(6):979-87.

38. Sponholz C, Schelenz C, Reinhart K, Schirmer U, Stehr SN. Catecholamine and volume therapy for cardiac surgery in Germany-results from a postal survey. PLoS One. 2014;9(8):e103996.

39. Vincent JL, Sakr Y, Sprung CL, Ranieri VM, Reinhart K, Gerlach H, et al. Sepsis in European intensive care units: results of the SOAP study. Crit Care Med. 2006;34(2):344-53.

\section{Tables}

Table 1: Study patients stratified by dopamine and noradrenaline use status 


\begin{tabular}{|c|c|c|c|c|}
\hline & $\begin{array}{l}\text { Dopamine } \\
(\mathrm{N}= \\
2750)\end{array}$ & $\begin{array}{l}\text { Dopamine }+ \\
\text { noradrenaline } \\
(\mathrm{N}=1903)\end{array}$ & $\begin{array}{l}\text { Noradrenaline } \\
(\mathrm{N}=9941)\end{array}$ & $\begin{array}{l}\mathrm{p}- \\
\text { value }\end{array}$ \\
\hline Year = $2019(\%)$ & $(56)^{1546}$ & $1092(57)$ & $6100(61)$ & $<0.001$ \\
\hline Age (mean years, SD) & $\begin{array}{l}69.6 \\
(12.4)\end{array}$ & $69.6(12.6)$ & $69.3(13.6)$ & 0.488 \\
\hline Gender (Male, \%) & $\begin{array}{l}1788 \\
(65.0)\end{array}$ & $\begin{array}{l}1261 \\
(66.3)\end{array}$ & $\begin{array}{l}6507 \\
(65.5)\end{array}$ & 0.677 \\
\hline Weight (mean kg, SD) & $(12.7)^{59.2}$ & $60.2(13.9)$ & $58.6(13.9)$ & $<0.001$ \\
\hline Height (mean cm, SD) & $\begin{array}{l}160.5 \\
(10.3)\end{array}$ & $160.9(10.2)$ & $160.7(10.1)$ & 0.309 \\
\hline \multicolumn{5}{|l|}{ Comorbidities (\%) } \\
\hline Acquired Immune Deficiency Syndrome & $1(0)$ & $3(0)$ & $9(0)$ & 0.393 \\
\hline Congestive heart failure & $(4)^{115}$ & $73(4)$ & $249(3)$ & $<0.001$ \\
\hline Respiratory failure & $(1)^{29}$ & $17(1)$ & $236(2)$ & $<0.001$ \\
\hline Cirrhosis & $(1)^{19}$ & $18(1)$ & $209(2)$ & $<0.001$ \\
\hline Use of immunosuppressants & $(8)^{210}$ & $93(5)$ & $861(9)$ & $<0.001$ \\
\hline Hemodialysis & $(6)^{177}$ & $159(8)$ & $781(8)$ & 0.022 \\
\hline Acute leukemia or lymphoma & $(1)^{16}$ & $25(1)$ & $213(2)$ & $<0.001$ \\
\hline Cancer with metastases & (3) ${ }^{72}$ & $39(2)$ & $338(3)$ & 0.002 \\
\hline $\begin{array}{l}\text { Days before ICU after hospital } \\
\text { admission (mean days, SD) }\end{array}$ & $(17.5)$ & $9.2(17.7)$ & $9.4(27.2)$ & 0.001 \\
\hline $\begin{array}{l}\text { Code blue or activation of Rapid Response } \\
\text { Team / Medical Emergency Team (\%) }\end{array}$ & $(1.3)^{35}$ & $62(3.3)$ & $648(6.5)$ & $<0.001$ \\
\hline $\begin{array}{l}\text { Cardiopulmonary resuscitation prior to ICU } \\
\text { admission (\%) }\end{array}$ & $(3.2)^{87}$ & $140(7.4)$ & $731(7.4)$ & $<0.001$ \\
\hline Reason for ICU admission (\%) & & & & $<0.001$ \\
\hline Transfer from ward & $(6)^{153}$ & $257(14)$ & $2061(21)$ & \\
\hline
\end{tabular}


Transfer from emergency room

Elective surgery

Urgent surgery

Other
$296(16)$
$2636(27)$

(11)

(66)

$984(52)$

$3033(31)$
(14)
$287(15)$
1596 (16)

$90 \quad 79(4) \quad 615(6)$

Diagnosis code (\%)

Cardiovascular

(66)

1817

$1421(75)$

$4128(42) \quad<0.001$

\section{Valvular surgery}

Coronary artery bypass graft surgery

Cardiac arrest

Infection

Post-surgery, Gastrointestinal tract

perforation/rupture

Bacterial pneumonia

Septic shock

Other

Post-surgery, gastrointestinal tumor

Other respiratory disease

Post-surgery,

oral/pharyngeal/nasal/trachea

APACHE III (mean, SD)

SAPS II (mean, SD)

Mechanical ventilation during the first 24

hours (\%)

AKI during the first 24 hours (\%)

Adrenaline during the first 24 hours (\%)

Dobutamine during the first 24 hours (\%)
565

294

365

902

780

585

(3)

63

277

106

$207(11)$

$2709(27) \quad<0.001$
34

10

3

(31)

373

9

86

64.9

(22.8)

35.9

(14.4)

(80)

(2)

42 (2)

810 (29)

Page 16/23
54

508 
Table Notes. SD: Standard Deviation, APACHE III: Acute Physiological Assessment and Chronic Health Evaluation, SAPS II: Simplified Acute Physiology Score. ICU: Intensive care unit, AKI: Acute kidney injury

Table 2: Multivariable logistic analysis with the generalized estimating equation: predictors of in-hospital mortality 
Death at hospital discharge

Predictors

(Intercept)

Age

Male gender

Comorbidities

Acquired Immune Deficiency Syndrome

Congestive heart failure

Respiratory failure

Cirrhosis

Use of immunosuppressants

Hemodialysis

Acute leukemia or lymphoma

Cancer with metastases

Days before ICU after hospital admission

Cardiopulmonary resuscitation prior to ICU admission

Reason for ICU admission (compared to others)

Transfer from the ward

Admission from the emergency room

Admission following elective surgery

Admission following urgent surgery

Diagnosis code (Not stated as reference)

Cardiovascular

Infection

APACHE III score

Serum lactate level

Mechanical ventilation during the first 24 hours

Acute kidney injury during the first 24 hours
Odds

Ratios

0.02

1.00

1.04

4.29

$2.17-8.48$

1.77

1.44

1.60

1.41

1.40

1.85

1.84

1.01

1.26

$1.38-2.28$

$1.06-1.95$

$1.22-2.09$

$1.17-1.70$

$1.17-1.67$

$1.28-2.66$

$1.36-2.50$

$1.00-1.01$

$0.98-1.60$

0.79

$0.66-0.93$

0.25

$0.21-0.31$

0.67

$0.56-0.81$

0.93

$0.72-1.19$

$0.93 \quad 0.72-1.19$


Dopamine use (compared to no use)

Dopamine (<= $5 \mathrm{microg} / \mathrm{kg} / \mathrm{min})$

Dopamine (More than 5 but equal to or less than 15 $\mathrm{microg} / \mathrm{kg} / \mathrm{min}$ )

$\mathrm{N}_{\text {Facility.ID }}$ 56

Observations 14374

Table Notes. ICU: Intensive care unit, APACHE III: Acute Physiological Assessment and Chronic Health Evaluation

Table 3. Baseline characteristics of propensity-matched groups for dopamine use 


\begin{tabular}{|c|c|c|c|}
\hline & $\begin{array}{l}\text { No } \\
\text { dopamine } \\
(\mathrm{N}=3322)\end{array}$ & $\begin{array}{l}\text { Dopamine } \\
(\mathrm{N}=3322)\end{array}$ & SMD \\
\hline Year = $2019(\%)$ & $\begin{array}{r}1901 \\
(57.2)\end{array}$ & $\begin{array}{c}2039 \\
(61.4)\end{array}$ & 0.085 \\
\hline Age (mean years, SD) & $69.0(12.6)$ & $69.5(12.2)$ & 0.038 \\
\hline Gender (Male, \%) & $\begin{array}{r}2222 \\
(66.9)\end{array}$ & $\begin{array}{r}2199 \\
(66.2)\end{array}$ & 0.015 \\
\hline Weight (mean kg, SD) & $60.2(13.3)$ & $59.7(13.3)$ & 0.039 \\
\hline Height (mean cm, SD) & $161.4(9.9)$ & $\begin{array}{l}160.7 \\
(10.2)\end{array}$ & 0.067 \\
\hline \multicolumn{4}{|l|}{ Comorbidities (\%) } \\
\hline Acquired Immune Deficiency Syndrome & $1(0.0)$ & $3(0.1)$ & 0.025 \\
\hline Congestive heart failure & $96(2.9)$ & $137(4.1)$ & 0.067 \\
\hline Respiratory failure & $47(1.4)$ & $39(1.2)$ & 0.021 \\
\hline Cirrhosis & $42(1.3)$ & $28(0.8)$ & 0.041 \\
\hline Use of immunosuppressants & $218(6.6)$ & $236(7.1)$ & 0.021 \\
\hline On hemodialysis & $248(7.5)$ & $224(6.7)$ & 0.028 \\
\hline Lymphoma or acute leukemia & $26(0.8)$ & $32(1.0)$ & 0.019 \\
\hline Cancer with metastasis & $50(1.5)$ & $70(2.1)$ & 0.045 \\
\hline Days before ICU after ICU admission (mean, SD) & $7.9(17.5)$ & $8.3(17.5)$ & 0.019 \\
\hline $\begin{array}{l}\text { Code blue or Rapid Response Team / Medical Emergency } \\
\text { Team (\%) }\end{array}$ & $115(3.5)$ & $84(2.5)$ & 0.055 \\
\hline Cardiopulmonary resuscitation prior to ICU admission (\%) & $171(5.1)$ & $200(6.0)$ & 0.038 \\
\hline Reason for ICU admission (\%) & & & 0.071 \\
\hline Transfer from ward & $252(7.6)$ & $275(8.3)$ & \\
\hline Transfer from emergency room & $\begin{array}{c}407 \\
(12.3)\end{array}$ & $\begin{array}{r}420 \\
(12.6)\end{array}$ & \\
\hline Elective surgery & $\begin{array}{r}2007 \\
(60.4)\end{array}$ & $\begin{array}{r}1954 \\
(58.8)\end{array}$ & \\
\hline Urgent surgery & $\begin{array}{r}560 \\
(16.9)\end{array}$ & $\begin{array}{r}540 \\
(16.3)\end{array}$ & \\
\hline Other & $96(2.9)$ & $133(4.0)$ & \\
\hline
\end{tabular}




\begin{tabular}{|c|c|c|c|}
\hline Cardiovascular & $\begin{array}{r}2325 \\
(70.0)\end{array}$ & $\begin{array}{c}2329 \\
(70.1)\end{array}$ & 0.003 \\
\hline Valvular surgery & 678 & 702 & \\
\hline Coronary artery bypass graft & 573 & 460 & \\
\hline Elective surgery, aortic aneurysm & 273 & 211 & \\
\hline Infection & $238(7.2)$ & $217(6.5)$ & 0.025 \\
\hline Gastrointestinal perforation / rupture & 83 & 70 & \\
\hline Aspiration pneumonia & 34 & 34 & \\
\hline Bacterial pneumonia & 36 & 30 & \\
\hline APACHE II (mean, SD) & $18.7(7.5)$ & $18.8(7.8)$ & 0.010 \\
\hline APACHE III (mean, SD) & $72.7(27.7)$ & $73.8(28.7)$ & 0.039 \\
\hline SAPS II (mean, SD) & $41.3(16.8)$ & $41.7(17.5)$ & 0.023 \\
\hline Mechanical ventilation during the first 24 hours (\%) & $\begin{array}{c}3265 \\
(98.3)\end{array}$ & $\begin{array}{c}3266 \\
(98.3)\end{array}$ & 0.002 \\
\hline AKI during the first 24 hours (\%) & $168(5.1)$ & $151(4.5)$ & 0.024 \\
\hline Adrenaline during the first 24 hours (\%) & $129(3.9)$ & $107(3.2)$ & 0.036 \\
\hline Dobutamine during the first 24 hours (\%) & $1470(44.3)$ & $1422(42.8)$ & 0.029 \\
\hline Noradrenaline during the first 24 hours (\%) & $3322(100)$ & $1383(41.6)$ & \\
\hline
\end{tabular}

Table Notes. SMD: Standard Mean Difference, SD: Standard Deviation, APACHE III: Acute Physiological Assessment and Chronic Health Evaluation, SAPS II: Simplified Acute Physiology Score. ICU: Intensive care unit, AKI: Acute kidney injury

Table 4: Outcomes in propensity-matched analysis 


$$
\begin{array}{lll}
\text { No dopamine } & \text { Dopamine } & \mathrm{p}- \\
(\mathrm{N}=3322) & (\mathrm{N}=3322) & \text { value }
\end{array}
$$

Death at time of hospital discharge (\%)

$$
397
$$

(12.0)

432

0.207

Death at time of ICU discharge (\%)

$200(6.0)$

(13.0)

ICU Length of stay (mean days, SD)

$6.5(10.0)$

$224(6.7)$

0.248

Hospital Length of stay (mean days, SD)

42.2

(43.7)

$7.4(10.9)$

0.001

Duration of the first mechanical ventilation (mean days, SD)

$3.3(9.5)$

0.294

$3.6(8.1)$

0.229

Table Notes. ICU: Intensive care unit

\section{Figures}

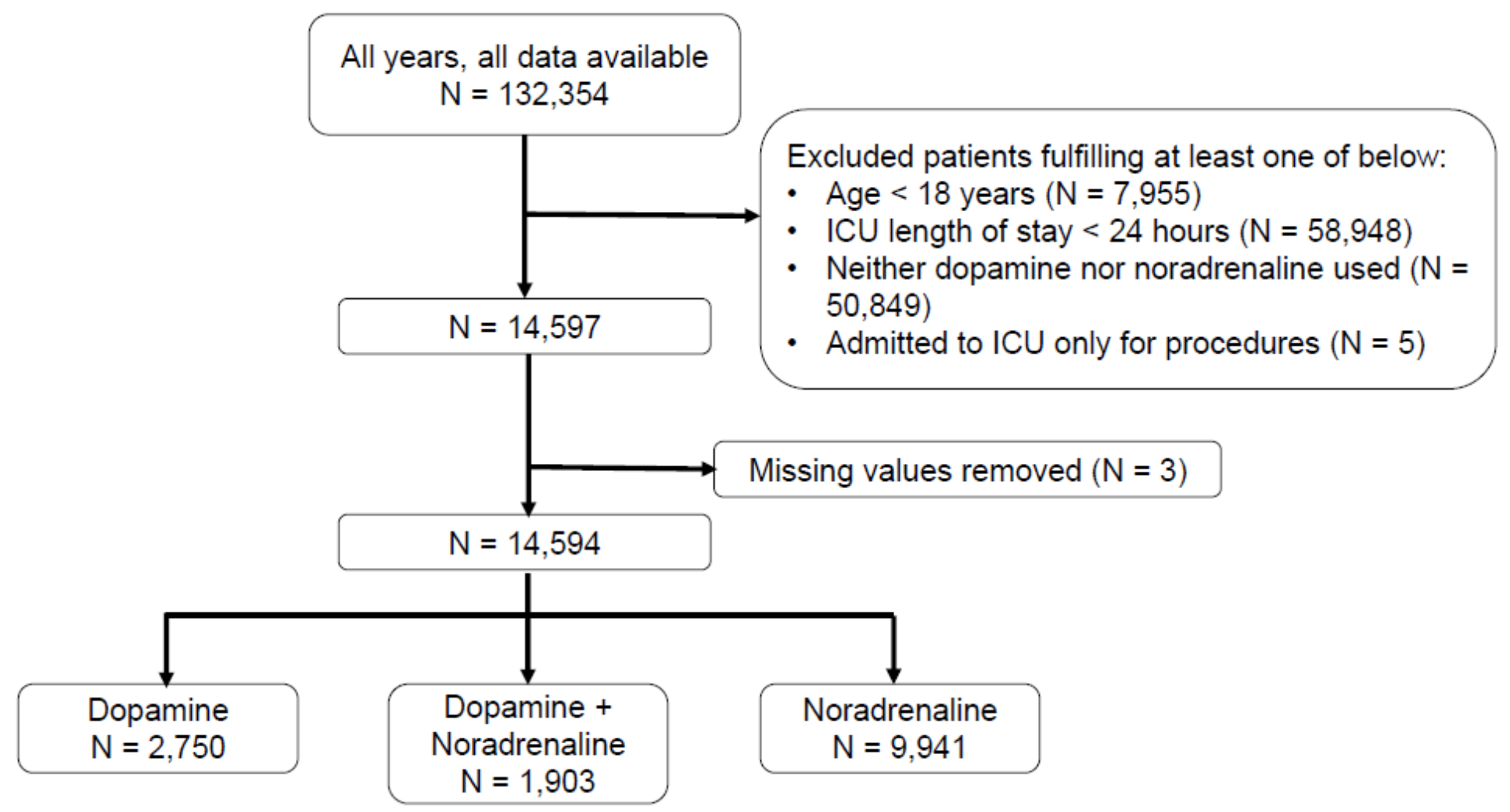

\section{Figure 1}

Flow diagram of the patient inclusion and exclusion process

Legends. ICU: Intensive Care Unit 


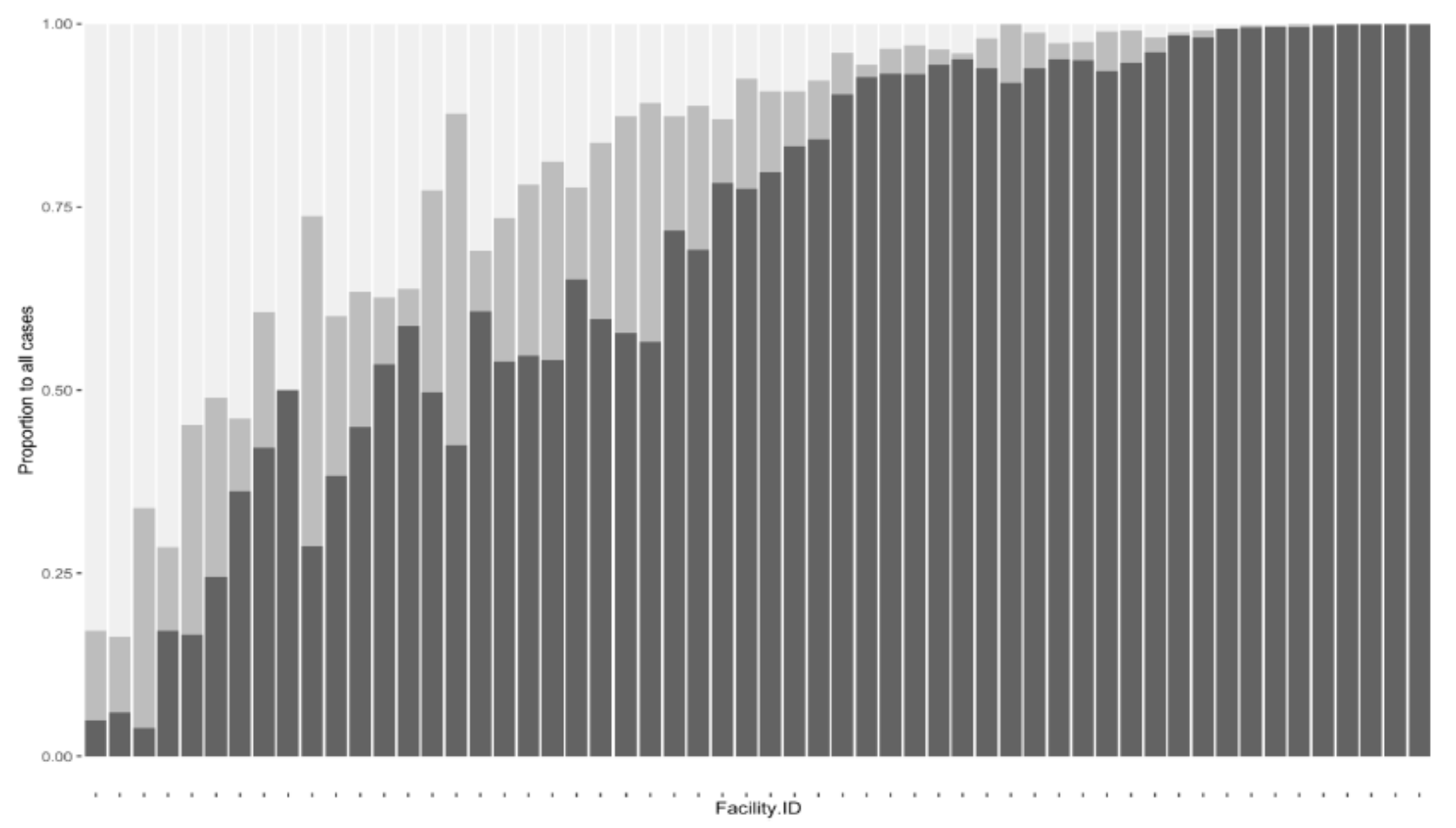

Figure 2

Proportion of patients treated with dopamine (light grey), dopamine and noradrenaline (grey), and noradrenaline (dark grey).

Legends. $\mathrm{X}$ axis: Facility identification number. $\mathrm{Y}$ axis: Proportion of patients to all cases.

\section{Supplementary Files}

This is a list of supplementary files associated with this preprint. Click to download.

- CCSupplDopamineSuzuki.docx 